Article

\title{
Spray Drying and Spout-Fluid Bed Drying Microencapsulation of Mexican Plum Fruit (Spondias purpurea L.) Extract and Its Effect on In Vitro Gastrointestinal Bioaccessibility
}

\author{
Sthefany Leticia Aguilera-Chávez ${ }^{1}$, Tzayhri Gallardo-Velázquez ${ }^{2} \mathbb{D}$, Ofelia Gabriela Meza-Márquez ${ }^{1, * \mathbb{D}}$ \\ and Guillermo Osorio-Revilla ${ }^{1, *(\mathbb{D})}$
}

1 Departamento de Ingeniería Bioquímica, Escuela Nacional de Ciencias Biológicas-Zacatenco, Instituto Politécnico Nacional, Av. Wilfrido Massieu S/N, Esq. Cda. Miguel Stampa Col., Unidad Profesional Adolfo López Mateos, Zacatenco, Alcaldía Gustavo A. Madero, Mexico City C.P. 07738, Mexico; qa.sthef@gmail.com

2 Departamento de Biofísica, Escuela Nacional de Ciencias Biológicas-Santo Tomás, Instituto Politécnico Nacional, Prolongación de Carpio y Plan de Ayala S/N, Col. Santo Tomás Alcaldía Miguel Hidalgo, Mexico City C.P. 11340, Mexico; gtzayhri@yahoo.com

* Correspondence: ogmmz@yahoo.com.mx (O.G.M.-M.); osorgi@gmail.com (G.O.-R.); Tel.: +52-(55)-5729-6000 (ext. 57877) (O.G.M.-M.); +52-(55)-5729-6000 (ext. 57817) (G.O.-R.)

check for updates

Citation: Aguilera-Chávez, S.L.; Gallardo-Velázquez, T.; MezaMárquez, O.G.; Osorio-Revilla, G. Spray Drying and Spout-Fluid Bed Drying Microencapsulation of Mexican Plum Fruit (Spondias purpurea L.) Extract and Its Effect on In Vitro Gastrointestinal

Bioaccessibility. Appl. Sci. 2022, 12, 2213. https://doi.org/10.3390/ app12042213

Academic Editor: Catarina Guerreiro Pereira

Received: 15 January 2022

Accepted: 17 February 2022

Published: 20 February 2022

Publisher's Note: MDPI stays neutral with regard to jurisdictional claims in published maps and institutional affiliations.

Copyright: (c) 2022 by the authors. Licensee MDPI, Basel, Switzerland. This article is an open access article distributed under the terms and conditions of the Creative Commons Attribution (CC BY) license (https:// creativecommons.org/licenses/by/ $4.0 /)$.

\begin{abstract}
The Mexican plum (Spondias purpurea L.) is a source of phenolic compounds; however, these compounds are susceptible to various factors (humidity, temperature, light, oxygen), as well as the digestion process, which can modify their bioaccessibility. This study aimed to extract and microencapsulate the phenolic compounds (PC), total anthocyanins (TA), ascorbic acid (AA), dehydroascorbic acid (DHA) and total vitamin $\mathrm{C}(\mathrm{AA}+\mathrm{DHA})$ from Mexican plum ecotype "Cuernavaqueña" by spray drying (SD) and spout-fluid bed drying (SFB) and evaluate the bioaccessibility of these compounds by in vitro digestion. Optimal extraction conditions for bioactive compounds (BC) and antioxidant capacity (AC) were: three consecutive extractions at $40{ }^{\circ} \mathrm{C}$, for $90 \mathrm{~min}$ each, with $1 / 5$ solid-solvent ratio $(4 \mathrm{~g} / 20 \mathrm{~mL})$, and $40 \% v / v$ aqueous ethanol. The extract without the encapsulation process suffered a significant $(p \leq 0.05)$ decrease in bioactive compounds and antioxidant capacity after in vitro digestion. Microcapsules obtained by SFB showed better retention and encapsulation efficiencies coupled with better protection against the digestion process. Microencapsulation by SFB protects the BC of Mexican plum, and it could be used in the food industry as ingredient to develop functional foods.
\end{abstract}

Keywords: Spondias purpurea L.; microencapsulation; spray drying; spouted bed; in vitro digestion; bioactive compounds; antioxidant capacity

\section{Introduction}

Mexican plum fruit (Spondias purpurea L.) is an oblong, round, ellipsoidal or ovoid shape, 2 to $5 \mathrm{~cm}$ long and 2 to $4 \mathrm{~cm}$ wide [1,2], with a smooth or semi-smooth thin epicarp (peel) that can be yellow, orange, light red or purple in color. The pulp or mesocarp is thin (1-10 $\mathrm{mm})$, juicy and with a yellow color, and a bittersweet or sour taste. The endocarp is big, tough and rough [2,3]. In Mexico, nearly 30 ecotypes have been reported, differing primarily in the weight, color and size [4,5]. The Mexican plum ecotype "Cuernavaqueña" is a fruit with orange-red color epicarp when it is fully ripe, with a length of $4 \mathrm{~cm}$, which has a thin mesocarp ( $8 \mathrm{~mm}$ ) and a short postharvest life: between 1 and 4 days at $20^{\circ} \mathrm{C}$ when it is harvested fully ripe [5]. This ecotype is a good source of various phenolic compounds (PC) (acid gallic, kaempferol, quercetin and isorhamnetin) and total anthocyanins (TA) (cyanidin 3-glucoside, quercetin 3-glucoside) both in epicarp and pulp, which are natural antioxidants that are beneficial for health [6,7]. When extracted, these compounds are susceptible to 
different factors, such as humidity, temperature, light, oxygen or the digestion process, which can modify their stability and bioaccessibility $[8,9]$.

Thus, the beneficial effects from the antioxidant compounds can be evaluated through the analysis of bioaccessibility (amount of compounds released from a matrix into the gastrointestinal tract, becoming available for absorption) [10]. The bioaccessibility of bioactive compounds is important in food or formula design. Many of these compounds are susceptible to degradation because they are sensitive to oxygen, light, heat and water. These factors limit the shelf life and bioaccessibility of bioactive compounds, so they must be protected as ingredients and in food products. In addition, the food industry expects more and more complex properties (delayed release, stability, thermal protection) of bioactive ingredients and compounds. Often, these demands cannot be met by the direct addition of a bioactive ingredient, because these bioactive compounds must be protected before use. Protection could be achieved with microencapsulation.

Microencapsulation is considered an efficient way of protecting and preventing degradation of bioactive compounds (BC). Microencapsulation is a process in which a core material is coated by some kind of wall material, to form capsules in micrometer or nanometer scales [11]. There are various microencapsulation techniques, but spray drying is the most common method; another lower-cost alternative is spouted bed drying with a bed of inert solids. The major advantages of microencapsulation include ease of handling and storage, controlled release, enhanced bioavailability and absorption through cells. The choice of wall material is an important factor which is based on physico-chemical properties (such as solubility, molecular weight and emulsifying properties) and must be generally regarded as safe (GRAS), biodegradable and should not affect the taste or flavor of the encapsulated material [12]. Gum arabic (GA) is mainly used as a wall material because has excellent functional properties such as emulsification, negatively charged properties, low cost, high solubility and low viscosity $[13,14]$.

Sollano-Mendieta et al. [15] analyzed 12 ecotypes of Mexican plum, including "Cuernavaqueña", and reported that "Cuernavaqueña" had a higher concentration of phenolic compounds, flavonoids, anthocyanins and antioxidant capacity than other ecotypes, however, the bioactive compounds and antioxidant capacity decreased significantly after in vitro digestion. Other studies $[16,17]$ reported the microencapsulation by spouted bed drying and spray drying of bioactive compounds of Mexican plum juice, however, there are no studies about the microencapsulation of bioactive compounds extract of ecotype "Cuernavaqueña" and the in vitro digestion.

The aim of this study was to obtain the best conditions for maximizing the extraction of bioactive compounds from Mexican plum ecotype "Cuernavaqueña", compare the retention of these in the microcapsules obtained by both, spray drying and spouted bed drying with inert solids, and to analyze the protection given to $\mathrm{BC}$ and $\mathrm{AC}$ against in vitro digestion process.

\section{Materials and Methods}

\subsection{Chemical and Reagents}

2,6-dichlorophenolindophenol, L-ascorbic acid, O-phenylenediamine, ABTS (2,2'-azinobis-3-ethylbenxothiazoline-6-sulphonic acid), boric acid, Folin-Ciocalteu reagent, DPPH (2,2-diphenyl-1-picrylhydrazyl), bile salts, Trolox (6-hydroxy-2,5,7,8-tetramethylchroman-2carboxylic acid) and all enzymes ( $\alpha$-amylase, pepsin, pancreatin) used for in vitro digestion were purchased from Sigma-Aldrich Co. (St. Louis, MO, USA). Sodium acetate, gallic acid, sodium bicarbonate, ammonium carbonate, calcium chloride, magnesium chloride, potassium chloride, sodium chloride, monopotassium phosphate, potassium persulfate, iodine and potassium iodate were obtained from Meyer (Mexico City, Mexico). Hydrochloric acid, ethanol, methanol and sodium hydroxide were from Reproquifin (Mexico City, Mexico). All chemicals and solvents were of analytical grade. 


\subsection{Samples}

Mexican plum fruits (Spondias purpurea L.) "Cuernavaqueña" ecotype were obtained in Chilpancingo, Guerrero, México. Fruits were obtained fully ripe, with no evident mechanical damage, pathogens or damage caused by insects.

\subsection{Preparation of Mexican Plum Fruits for Extraction of Bioactive Compounds}

Fruits were washed with a $1 \%(v / v)$ sodium hypochlorite solution, rinsed three times with distilled water, and left for drying at room temperature. Afterward, pulp and peel were separated from seed and dried at $40^{\circ} \mathrm{C}$ in an oven (OV-12 Lab Companion, Jeio Tech, Daejeon, Korea) for $24 \mathrm{~h}$. Dried pulp and peel were pulverized together in a food processor (MBR-1101, Magic Bullet, Los Angeles, CA, USA) and sieved in a 60-mesh sieve $(250 \mu \mathrm{m})$. The material retained in the sieve was milled and sieved again. This process was repeated until most of the dried pulp and peel passed the sieve. The obtained powder was stored at $-20{ }^{\circ} \mathrm{C}$ in a Ziploc bag until use.

\subsection{Extraction of Bioactive Compounds}

The bioactive compounds from pulp and peel Mexican plum were extracted by solidliquid extraction using the conditions reported by Hernández-Ruiz et al. [18]. Samples were mixed using 1:5 sample:solvent ratio $(4 \mathrm{~g}: 20 \mathrm{~mL})$ with $80 \%$ aqueous ethanol. The mixture was macerated for different times (10, 20, 40, 60, 90, 120 and $240 \mathrm{~min}$ ) at room temperature with continuous shaking. After each extraction time, samples were centrifuged (MS-3400, Cole-Palmer, Vernon Hills, IL, USA) at $1796 \times g$ (3400 rpm) for $20 \mathrm{~min}$. The supernatant was filtered through Whatman paper No. 6 (Whatman Ltd., Maidstoine, UK) and kept in an amber glasse bottle until quantifying PC. The process was carried out in triplicate.

\subsection{Re-Extraction Frequency for Maximum Phenolic Yield}

The number of consecutive extractions (for extracting more than $95 \%$ of PC) was determined from the five consecutive extractions, quantifying PC as the response variable in each extraction. The extraction of the response variable was expressed as the cumulative percentage of PC obtained in each extraction. The process was carried out in triplicate.

\subsection{Optimization of Extraction of Phenolic Compounds from Mexican Plum Powder}

Once the best extraction time and number of extractions were known, the extraction conditions were optimized, using a $3^{2}$ factorial design with replicates at all points. Factors and levels were: extraction temperature $\left(30,40\right.$ and $\left.50{ }^{\circ} \mathrm{C}\right)$ and solvent concentration (aqueous ethanol: 40, 60 and $80 \% v / v$ ). In total, 27 experiments were carried out to achieve the optimum conditions for the maximum amount of PC in the extraction process.

\subsection{Preparation of Extract for Microencapsulation Process}

Since PC concentration in the optimized extract was low for the encapsulation process, it was necessary to concentrate the extract to obtain a PC content in the extract of about $2 \mathrm{mg}$ gallic acid equivalents (GAE)/g (similar to PC content in pomegranate extract encapsulated by Robert et al. [19]) to ensure a good PC content in the microcapsules. For this, a rotavapor was used (Rotavapor ${ }^{\circledR}$ R-300, BUCHI, Flawil, Switzerland) to monitor the boiling temperature of the solution, to ensure that all ethanol present in the extract was eliminated. This was necessary to avoid precipitation of gum arabic (GA), used as wall material, in the solution to be dried. A $30 \% \mathrm{~W} / \mathrm{W}$ solution of GA was prepared and left to stand $3 \mathrm{~h}$ under vacuum to eliminate air bubbles. Then, the GA solution was mixed with the concentrated Mexican plum extract to obtain a final concentration of $10 \% \mathrm{w} / \mathrm{W}$ of wall material in the solution to be dried. This corresponded to a core (dry solids of extract):encapsulating agent (solids of GA) ratio of 1:4. The amounts used of GA and Mexican plum extract required to prepare the solutions were calculated with a mass balance. 


\subsection{Microencapsulation}

\subsubsection{Microencapsulation by Spray Drying}

The spray drying microencapsulation of Mexican plum extract was performed with a semi-pilot spray dryer (Mobile Minor MM, GEA, Gladsaxe, Denmark). The equipment has a cylindric-conical drying chamber of $0.8 \mathrm{~m}$ diameter, $0.62 \mathrm{~m}$ height of the cylindrical section and $0.72 \mathrm{~m}$ height of the bottom conical section. It is equipped with a two-fluid spray nozzle for external mixing, $30 \mathrm{~mm}$ diameter, $1 \mathrm{~mm}$ annular space for air flow and $1 \mathrm{~mm}$ orifice for liquid flow. The equipment works with a spray pressure of $0.5 \mathrm{~kg} / \mathrm{cm}^{2}$ and a cyclone separator to collect the powder. Microencapsulation by spray drying was performed at $170{ }^{\circ} \mathrm{C}$ inlet temperature and $80^{\circ} \mathrm{C}$ outlet temperature. These conditions were reported as the best drying conditions by Rigon and Zapata [20]. Microencapsulation runs were performed in triplicate. Powders were stored in sealed amber glass bottles and kept at $-20{ }^{\circ} \mathrm{C}$ until analysis.

\subsubsection{Microencapsulation by Spout-Fluid Bed Dryer with Inert Solids}

The spout-fluid bed drying microencapsulation of Mexican plum extract was accomplished in a spout-fluid bed dryer which consists of a cylindrical Perspex chamber with a perforated conical base and a short central tube submerged in the inert solids bed (Figure 1). The equipment was described in previous works [21,22]. The bed of inert solids consisted of copolymer of tetrafluoroethylene and hexafluoropropylene pellets $\left(\mathrm{FEP}^{\circledR}\right.$, DuPont Company, Wilmington, DE, USA).

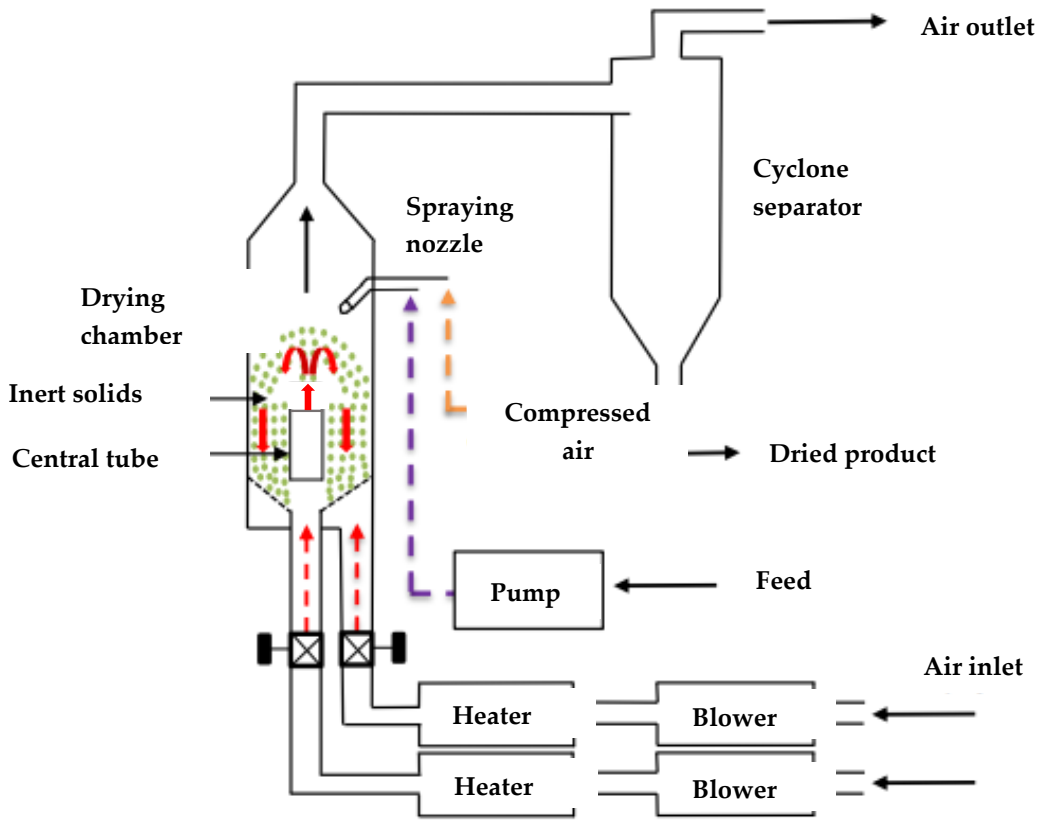

Figure 1. Schematic diagram of spout-fluid bed dryer with inert solids.

Spout-fluid bed drying experiment was performed using a static heigh $(\mathrm{H})$ of the inert solid bed of $1 \mathrm{H} / \mathrm{D}_{\mathrm{c}}$, a spray pressure of $0.5 \mathrm{~kg} / \mathrm{cm}^{2}$ and an inlet air flow velocity through the annular region equivalent to $0.7 \mathrm{U}_{\mathrm{mf}}$ (minimum fluidization velocity) with an inlet annular air temperature equal to the outlet drying temperature. The inlet airflow velocities through the spout were equivalent to $1.2 \mathrm{U}_{\mathrm{mst}}$ (minimum spouting velocity with draft tube). The inlet temperature was $160^{\circ} \mathrm{C}$ and the outlet temperature $90{ }^{\circ} \mathrm{C}$; these conditions were reported by Velázquez-Contreras et al. [23]. Microencapsulation runs were performed in triplicate. Powders were stored in sealed amber glass bottles and kept at $-20{ }^{\circ} \mathrm{C}$ until analysis. 
Analysis of Powders

Microcapsules obtained by both drying methods were reconstituted in water at the same solids concentration as in the initial solution before being dried. For each drying run, a 10\% $\mathrm{W} / \mathrm{W}$ GA solution (empty microcapsules) was also dried and used as a blank.

\subsection{Analytical Methods}

\subsubsection{Total Phenolic Compounds}

Total phenolic content was determined using Folin-Ciocalteu reagent as described by González-Montelongo et al. [24]. For the analysis, $0.2 \mathrm{~mL}$ of sample was mixed with $0.8 \mathrm{~mL}$ of distilled water, followed by the addition of $0.2 \mathrm{~mL}$ of Folin-Ciocalteu reagent. After $6 \mathrm{~min}, 2 \mathrm{~mL}$ of sodium carbonate $(7 \% \mathrm{~W} / \mathrm{W})$ was added, and the sample final volume was adjusted to $5.2 \mathrm{~mL}$ with distilled water. Finally, the sample was left to stand for $60 \mathrm{~min}$ at room temperature in the dark. The absorbance was measured at $765 \mathrm{~nm}$ in a spectrophotometer (Jenway 320D, Staffordshire, UK) and the PC were quantified using a gallic acid standard calibration curve (absorbance $=111.4(\mathrm{mg}$ GAE $)+0.017, \mathrm{R}^{2}$ 99.9\%) The results were expressed as mg gallic acid equivalents per $\mathrm{g}$ dry weight (mg GAE/g $\mathrm{g}_{\mathrm{dw}}$ ). The analysis was performed in triplicate.

\subsubsection{Total Anthocyanins}

Total anthocyanin content was determined using the $\mathrm{pH}$ differential method reported by Giusti and Wrolstad [25] in 2 buffer systems: potassium chloride pH 1.0 and sodium acetate $\mathrm{pH}$ 4.5. For the analysis, $1 \mathrm{~mL}$ of sample was added in two volumetric flasks $(10 \mathrm{~mL})(\mathrm{A}$ and $\mathrm{B})$; the final volume of the flasks was adjusted with the buffers (one buffer in each flask) and left to stand for $15 \mathrm{~min}$ in the dark. The absorbance of the solutions was measured at 510 and $700 \mathrm{~nm}$. The results were expressed as $\mu$ g cyanidin-3-glycoside per $\mathrm{g}$ dry weight ( $\mu \mathrm{g}$ cya-3-glu/g $\mathrm{g}_{\mathrm{dw}}$ ) using Equation (1), with molar mass $449.2 \mathrm{~g} / \mathrm{mol}$ and molar absorptivity coefficient $26,900 \mathrm{~L} / \mathrm{mol} \cdot \mathrm{cm}$. The analysis was performed in triplicate:

$$
\left.\mathrm{A}=\left[\left(\mathrm{A}_{510 \mathrm{~nm}}-\mathrm{A}_{700 \mathrm{~nm}}\right)_{\mathrm{pH} 1.0}-\mathrm{A}_{510 \mathrm{~nm}}-\mathrm{A}_{700 \mathrm{~nm}}\right)_{\mathrm{pH} 4.5}\right]
$$

\subsubsection{Ascorbic Acid, Dehydroascorbic Acid, and Total Vitamin C}

Ascorbic acid and dehydroascorbic acid were determined using the microfluorometric method reported by Omaye et al. [26] and Zieliński [27]. For the total vitamin C analysis, $2 \mathrm{~mL}$ of sample was oxidized by the addition of $10 \mu \mathrm{L}$ of $0.1 \mathrm{~N}$ potassium iodide, followed by the addition of $5 \mu \mathrm{L} 0.5 \mathrm{M}$ sodium thiosulfate. Then, $500 \mu \mathrm{L}$ of oxidized sample was mixed with $500 \mu \mathrm{L}$ of $25 \%$ sodium acetate and the sample left to stand for 15 min in the dark at room temperature; after that, $200 \mu \mathrm{L}$ of $0.1 \% O$-phenylenediamine was added (to give a quinoxaline derivate) and left to stand again for $15 \mathrm{~min}$. The fluorescence was measured with excitation at $348 \mathrm{~nm}$ and emission at $423 \mathrm{~nm}$ in a fluorometer (Varioskan LUX, ThermoFisher Scientific, Arlington, TX, USA). Dehydroascorbic acid was assayed directly from the sample without any oxidation step. For each sample analyzed, a specific blank was prepared with boric acid. The difference between total vitamin $C$ and dehydroascorbic acid provided the ascorbic acid content. Total vitamin $\mathrm{C}$ and dehydroascorbic acid were quantified using an ascorbic acid standard curve (absorbance $=-3.24+1.34 \mu \mathrm{gDHA} / \mathrm{mL}$, $\mathrm{R}^{2}$ 99\%). The results were expressed as $\mu \mathrm{g}$ ascorbic acid, dehydroascorbic acid or total vitamin $\mathrm{C}$ per g dry weight ( $\mu \mathrm{g} \mathrm{AA} / \mathrm{g}_{\mathrm{dw}} ; \mu \mathrm{g} \mathrm{DHA} / \mathrm{g}_{\mathrm{dw}} ; \mu \mathrm{g}$ Total Vit $\mathrm{C} / \mathrm{g}_{\mathrm{dw}}$ ). The analyses were performed in triplicate.

\subsubsection{Antioxidant Capacity}

Antioxidant capacity was measured using two radical scavenging methods: ABTS [28] and DPPH [29] assays. For both methods, the wall material (GA) was previously precipitated with ethanol for ABTS assay or methanol for DPPH assay in the reconstituted microcapsules. The precipitation was necessary since the wall material is insoluble in these solvents, which are used for the preparation of the radicals [30,31]. After the precipitation, 
the solution was centrifugated at $1796 \times g(3400 \mathrm{rpm})$ for $10 \mathrm{~min}$ and filtered through a glass microfiber filter paper with $0.6 \mu \mathrm{m}$ pore size (ADVANTEC, Tokio, Japan). Aliquots of the filtrate were used for the analysis.

For the ABTS assay, the ABTS radical was produced by reacting $7 \mathrm{mM}$ ABTS solution with $140 \mathrm{mM}$ potassium persulfate $(2.45 \mathrm{mM}$ potassium persulfate final concentration) and leaving them to stand for $12 \mathrm{~h}$ at room temperature in the dark. Subsequently, the ABTS radical solution was diluted with ethanol to obtain an absorbance of $0.70( \pm 0.04)$ at $734 \mathrm{~nm}$. For the analysis, $3 \mathrm{~mL}$ of the ABTS radical solution was added to $0.3 \mathrm{~mL}$ of the sample and the solution was left to stand for 6 min in the dark. Finally, the absorbance was measured at $734 \mathrm{~nm}$.

For the DPPH assay, $3.9 \mathrm{~mL}$ of $0.06 \mathrm{mM}$ DPPH solution (previously diluted with methanol to obtain an absorbance of approximately 1.0) was added to $0.1 \mathrm{~mL}$ of the sample and left to stand for $60 \mathrm{~min}$ in the dark at room temperature. Finally, the absorbance was measured at $515 \mathrm{~nm}$.

The antioxidant capacity was determined for both methods using Trolox as standard. In both methods, a control with the addition of the solvent or distiller water (instead of extract or reconstituted microcapsules) was used. Results were expressed as $\mu$ moles of Trolox equivalents per $\mathrm{g}$ dry weight $\left(\mu \mathrm{mol} \mathrm{TE} / \mathrm{g}_{\mathrm{dw}}\right)$. The analyses were performed in triplicate.

\subsubsection{Retention and Encapsulation Efficiency}

Retention efficiency (RE) was calculated by determining the BC content in the solutions to be dried (extract + wall material) and in the reconstituted microcapsules. Results were expressed as percentages (Equation (2)):

$$
\operatorname{RE}(\%)=\left(\frac{\mathrm{BC} \text { content in microcapsules } / \mathrm{g}_{\mathrm{dw}}}{\mathrm{BC} \text { content in solution to be dried } / \mathrm{g}_{\mathrm{dw}}}\right) \times 100
$$

Encapsulation efficiency (EE) was calculated by determining the difference between the $\mathrm{BC}$ content retained in the microcapsules and the $\mathrm{BC}$ content on the surface of the microcapsules, divided by the $\mathrm{BC}$ content in the solution to be dried. Results were expressed as percentage (Equation (3)):

$\mathrm{EE}(\%)=\left(\frac{\mathrm{BC} \text { content in microcapsules } / \mathrm{g}_{\mathrm{dw}}-\mathrm{BC} \text { content on surface microcapsules } / \mathrm{g}_{\mathrm{dw}}}{\mathrm{BC} \text { content in solution to be dried } / \mathrm{g}_{\mathrm{dw}}}\right) \times 100$

where BC: bioactive compounds

Determinations of RE and EE were performed in triplicate.

\subsubsection{Moisture Content and Water Activity $\left(\mathrm{a}_{\mathrm{w}}\right)$}

Moisture content was determined using a thermobalance (OHAUS MB200, Montville, $\mathrm{NJ}$, USA), placing $0.5 \mathrm{~g}$ of the sample at $110^{\circ} \mathrm{C}$ until a constant weight (difference $<0.01 \mathrm{~g}$ ) was obtained. Water activity $\left(\mathrm{a}_{\mathrm{w}}\right)$ was measured using an AquaLab Cx-2 (Decagon, Pullman, WA, USA). Both determinations were performed in triplicate.

\subsubsection{Particle Size Distribution}

Particle size distribution was determined using a laser diffraction particle size analyzer (IM 0262006 series, Malvern, UK) with a $100 \mathrm{~mm}$ lens for the microcapsules obtained by spray drying and $300 \mathrm{~mm}$ lens for the microcapsules obtained by spout-fluid bed. The particle size distribution, Sauter diameter $(\mathrm{D}[3,2])$ and equivalent spherical diameter $(\mathrm{D}[4,3])$ were determined using hexane as a dispersant (REASOL, Mexico City, Mexico). The analysis was performed in triplicate. 


\subsubsection{Morphological Analyzes of Microcapsules}

The surface morphology of the microcapsules was observed with a scanning electron microscope (SEM) (JSM-5800LV, Jeol, Peabody, MA, USA) set to an acceleration voltage of $5 \mathrm{kV}$. Microcapsules were fixed in double-faced adhesive tape stubs, coated with gold and, finally, observed using a $500 \times$ and $1000 \times$ magnification.

\subsection{In Vitro Gastrointestinal Digestion}

The bioaccessibility of bioactive compounds and antioxidant capacity of Mexican plum powder, Mexican plum extract and microcapsules was performed according to the methodology by Minekus et al. [10] which simulates the digestion in mouth (oral phase), stomach (gastric phase) and small intestine (intestinal phase). Analyses of all phases were performed in triplicate.

Digestion was started by mixing $5 \mathrm{~g}$ of the sample (microcapsules, Mexican plum powder or Mexican plum extract) with $2.5 \mathrm{~mL}$ of Simulated Salivary Fluid (SSF), followed by the addition of $0.5 \mathrm{~mL}$ of $\alpha$-amylase $(1500 \mathrm{U} / \mathrm{mL}) ; 25 \mu \mathrm{L} \mathrm{CaCl}_{2}(0.3 \mathrm{M})$ and $0.975 \mathrm{~mL}$ of distiller water (to obtain a suspension with a final volume of $10 \mathrm{~mL}$ ). The suspension was adjusted to $\mathrm{pH} 7$ and gently stirred for $2 \mathrm{~min}$ at $37^{\circ} \mathrm{C}$. In the gastric phase, $7.5 \mathrm{~mL}$ of Simulated Gastric Fluid (SGF) was mixed with the oral phase $(10 \mathrm{~mL})$, followed by the addition of $1.6 \mathrm{~mL}$ of bovine pepsin $(25000 \mathrm{U} / \mathrm{mL}), 5 \mu \mathrm{LaCl}_{2}(0.3 \mathrm{M}), 0.2 \mathrm{~mL}$ of $\mathrm{HCl}(1 \mathrm{M})$ and $0.695 \mathrm{~mL}$ of distiller water (to obtain a suspension with a final volume of $20 \mathrm{~mL}$ ). The suspension was adjusted to $\mathrm{pH} 2$ with $\mathrm{HCl}(1 \mathrm{M})$ and gently stirred for $2 \mathrm{~h}$ at $37^{\circ} \mathrm{C}$. After $2 \mathrm{~h}$, an aliquot of $10 \mathrm{~mL}$ was taken and immersed on ice for $10 \mathrm{~min}$, then the $\mathrm{pH}$ was adjusted to 9 with $\mathrm{NaOH}(1 \mathrm{M})$ to stop the reaction. The aliquot was centrifuged at $1796 \times g(3400 \mathrm{rpm})$ for $10 \mathrm{~min}$. The supernatant was used for the analysis of phenolics compounds, total anthocyanins, ascorbic acid, dehydroascorbic acid and antioxidant capacity (ABTS, DPPH).

For the small intestinal digestion phase, $5.5 \mathrm{~mL}$ of the SGF was mixed with $10 \mathrm{~mL}$ of Simulated Intestinal Fluid (SIF), followed by the addition of $2.5 \mathrm{~mL}$ pancreatin $(800 \mathrm{U} / \mathrm{mL})$, $1.25 \mathrm{~mL}$ of bile salts $(160 \mathrm{mM}), 20 \mu \mathrm{L} \mathrm{CaCl}_{2}(0.3 \mathrm{M}), 75 \mu \mathrm{L} \mathrm{NaOH}(1 \mathrm{M})$ and $0.655 \mathrm{~mL}$ of distilled water (to obtain a suspension with a final volume of $20 \mathrm{~mL}$ ). The suspension was adjusted to $\mathrm{pH} 7$ and gently stirred for $2 \mathrm{~h}$ at $37^{\circ} \mathrm{C}$. After this time, the sample was immersed on ice for $10 \mathrm{~min}$, then the $\mathrm{pH}$ was adjusted to 9 with $\mathrm{NaOH}(1 \mathrm{M})$ to inactivate the enzymes. The sample was centrifuged at $1796 \times g$ ( $3400 \mathrm{rpm}$ ) for $10 \mathrm{~min}$. The supernatant was used for the analysis of phenolics compounds, total anthocyanins, ascorbic acid, dehydroascorbic acid and antioxidant capacity (ABTS, DPPH).

The release of phenolics compounds, total anthocyanins, ascorbic acid, dehydroascorbic acid and antioxidant capacity during the in vitro digestion process was evaluated with the recovery index (\%R) and bioaccessibility index (\%B) calculated with Equations (4) and (5), respectively [32]:

$$
\begin{aligned}
& \% R=\frac{A}{C} \times 100 \\
& \% B=\frac{B}{C} \times 100
\end{aligned}
$$

where A is the content of the compounds (phenolics, total anthocyanins, ascorbic acid, dehydroascorbic acid or antioxidant capacity) released after gastric digestion, B is the content of the compounds (phenolics, total anthocyanins, ascorbic acid, dehydroascorbic acid or antioxidant capacity) released after intestinal digestion and $C$ is the content of the compounds (phenolics, total anthocyanins, ascorbic acid, dehydroascorbic acid or antioxidant capacity) before digestion.

\subsection{Statistical Analysis}

Results were expressed as the mean value \pm standard deviation. Significant differences between means were determined by analysis of variance (ANOVA) and the mean comparisons by Tukey's test at $95 \%$ confidence interval $(p \leq 0.05)$. Statical analyses were performed using Minitab statical software, V.18 (Minitab, Inc., State College, PA, USA). 


\section{Results and Discussion}

\subsection{Optimization of Extraction of Phenolic Compounds from Mexican Plum Powder}

From the five consecutive extractions performed, three extraction cycles were selected. With this number of extractions, $95 \%$ (3.0 $\left.\mathrm{mg} \mathrm{GAE} / \mathrm{g}_{\mathrm{dw}}\right)$ of PC present in pulp and peel powder of Mexican plum were extracted. Figure 2 shows the phenolic compounds accumulated percentage obtained in each extraction. Five consecutive extractions obtained $3.17 \mathrm{mg}$ $\mathrm{GAE} / \mathrm{g}_{\mathrm{dw}}$ (the summatory of the phenolic compounds obtained in the five extraction) and it was considered as the $100 \%$. The summatory of the three extractions was $3.01 \mathrm{mg}$ $\mathrm{GAE} / \mathrm{g}_{\mathrm{dw}}$, which are the $95 \%$ of the total of phenolic compounds extracted in the five consecutive extractions.

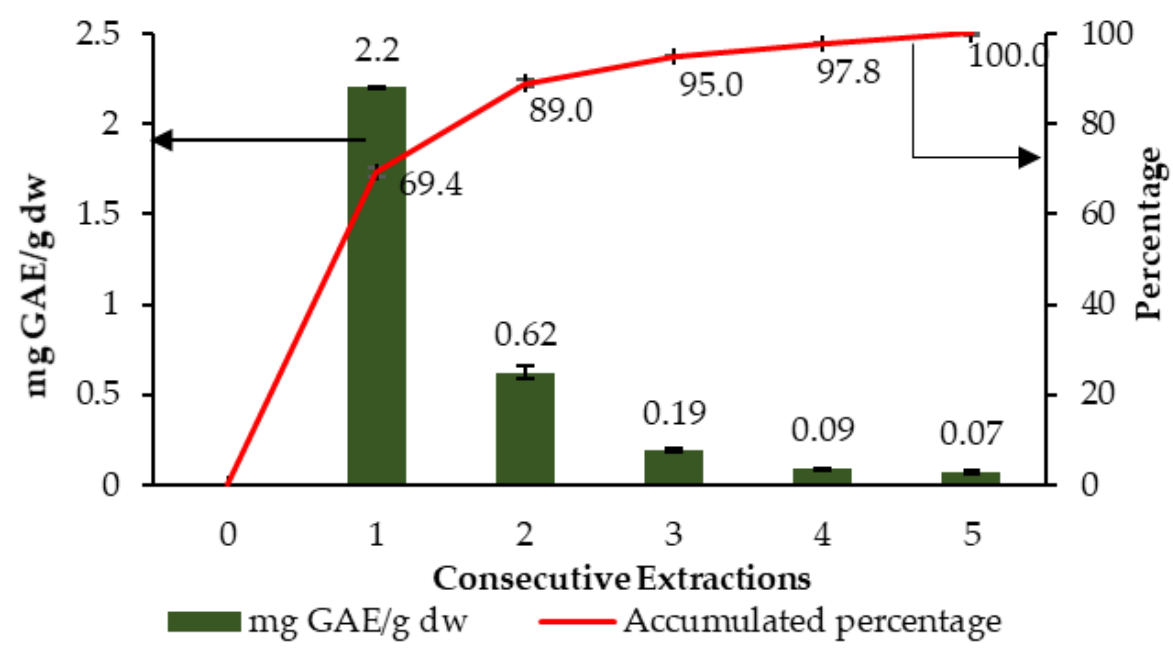

Figure 2. Phenolic compounds accumulated percentage obtained in each extraction.

The best extraction conditions obtained from the $3^{2}$ full factorial design, using Minitab V.18 were: extraction temperature at $40{ }^{\circ} \mathrm{C}$ and ethanol concentration $40 \%$, with three consecutive extractions, $90 \mathrm{~min}$ each. The predicted phenolic compounds' value was $0.59 \mathrm{mg} \mathrm{GAE} / \mathrm{mL}$ extract with a desirability value (D) of 0.9875 . The result obtained in the experimental validation of predicted PC was $0.58 \pm 0.01 \mathrm{mg}$ GAE $/ \mathrm{mL}$ extract. Experimental (using the optimum conditions) and theoretical results were similar, and no significant difference was observed.

\subsection{Characterization of Mexican Plum Powder (Pulp and Peel)}

Table 1 shows the results obtained for the characterization of the dried Mexican plum powder (pulp and peel) ("Cuernavaqueña" ecotype) based on dry weight $\left(\mathrm{d}_{\mathrm{w}}\right)$ and fresh weight $\left(\mathrm{f}_{\mathrm{w}}\right)$ in order to compare with other studies which based their results on fresh weight.

The value of the PC was similar to the content for Mexican plum reported by Stafussa et al. [33] (2.04 mg GAE/g $\left.\mathrm{g}_{\mathrm{fw}}\right)$ and lower than the content for Mexican plum ecotype "Cuernavaqueña" reported by Suárez-Vargas et al. [34] (2.39 $\mathrm{mg}$ GAE/g $\left./ \mathrm{g}_{\mathrm{fw}}\right)$. The value of TA, shown in Table 1, was lower than the results obtained in S. purpurea by MooHuchin et al. [35] (18 $\mu \mathrm{g}$ cya-3-glu $\left./ \mathrm{g}_{\mathrm{fw}}\right)$ and higher than that reported by Stafussa et al. [33] $\left(3 \mu \mathrm{g}\right.$ cya-3-glu $\left./ \mathrm{g}_{\mathrm{fw}}\right)$. Regarding the AA, DHA and total vitamin C content, most of the vita$\min C$ content reported by other authors is based only on the ascorbic acid content; therefore, only the values for AA shown in Table 1 were compared with other reports. AA obtained in the present work was lower than the values reported by Vasco et al. [36] (270-360 $\mu \mathrm{g}$ AA $\left./ \mathrm{g}_{\mathrm{fw}}\right)$ and Almeida et al. [37] (296 $\left.\mu \mathrm{g} \mathrm{AA} / \mathrm{g}_{\mathrm{fw}}\right)$ in S. mombin and S. purpurea, respectively. Regarding AC by ABTS and DPPH content, shown in Table 1, these were lower than the values for ecotype "Cuernavaqueña" reported by Suárez-Vargas et al. [34] (20.59 $\mu \mathrm{mol}$ $\mathrm{TE} / \mathrm{g}_{\mathrm{fw}}$ for ABTS and $14.72 \mu \mathrm{mol} \mathrm{TE} / \mathrm{g}_{\mathrm{fw}}$ for $\mathrm{DPPH}$ ). These differences in the content of bioactive compounds and antioxidant capacity may be due to the moisture content and the sample pre-treatment used in this work (freezing and dried at $40^{\circ} \mathrm{C}$ for $24 \mathrm{~h}$ ), which may 
degrade the bioactive compounds, in contrast to the previous authors who analyzed the fresh fruit. In addition, these differences can be due to the fruit characteristics (different ripeness state, harvest season, ecotype, among others) [4,34] and extraction conditions (temperature, time, solid-solvent ratio and type of solvent and concentration) [38].

Table 1. Bioactive compounds in dry Mexican plum powder (pulp and peel).

\begin{tabular}{|c|c|c|}
\hline \multirow{2}{*}{ Parameter } & \multicolumn{2}{|c|}{ Results } \\
\hline & Dry Weight & Fresh Weight \\
\hline $\mathrm{PC}\left(\mathrm{mg} \mathrm{GAE} / \mathrm{g}_{\mathrm{dw}}|| \mathrm{mg} \mathrm{GAE} / \mathrm{g}_{\mathrm{fw}}\right)$ & $6.14 \pm 0.39$ & $1.72 \pm 0.2$ \\
\hline TA $\left(\mu \mathrm{g}\right.$ cya-3-glu $/ g_{d w}|| \mu g$ cya-3-glu/g $\left.g_{f w}\right)$ & $18 \pm 3.4$ & $5 \pm 1.0$ \\
\hline $\mathrm{AA}\left(\mu \mathrm{g} \mathrm{AA} / \mathrm{g}_{\mathrm{dw}}|| \mu \mathrm{g} \mathrm{AA} / \mathrm{g}_{\mathrm{fw}}\right)$ & $561 \pm 49$ & $157 \pm 14$ \\
\hline $\mathrm{DHA}\left(\mu \mathrm{g}\right.$ DHA $\left./ g_{\mathrm{dw}}|| \mu \mathrm{g} \mathrm{DHA} / \mathrm{g}_{\mathrm{fw}}\right)$ & $2737 \pm 58$ & $766 \pm 16$ \\
\hline Total vitamin $\mathrm{C}\left(\mu \mathrm{g} \mathrm{AA}+\mathrm{DHA} / \mathrm{g}_{\mathrm{dw}}|| \mu \mathrm{g} \mathrm{AA}+\mathrm{DHA} / \mathrm{g}_{\mathrm{fw}}\right)$ & $3298 \pm 49$ & $923 \pm 14$ \\
\hline $\mathrm{AC}(\mathrm{ABTS})\left(\mu \mathrm{mol} \mathrm{TE} / \mathrm{g}_{\mathrm{dw}}|| \mu \mathrm{mol} \mathrm{TE} / \mathrm{g}_{\mathrm{fw}}\right)$ & $42.82 \pm 2.74$ & $11.99 \pm 0.77$ \\
\hline $\mathrm{AC}(\mathrm{DPPH})\left(\mu \mathrm{mol} \mathrm{TE} / \mathrm{g}_{\mathrm{dw}}|| \mu \mathrm{mol} \mathrm{TE} / \mathrm{g}_{\mathrm{fw}}\right)$ & $33.24 \pm 2.76$ & $9.31 \pm 0.77$ \\
\hline Moisture content $(\%)$ & \multicolumn{2}{|c|}{$4.75 \pm 0.69$} \\
\hline
\end{tabular}

TA: Total anthocyanins, PC: phenolic compounds, AA: ascorbic acid, DHA: dehydroascorbic acid, AA+DHA: total vitamin C, AC: antioxidant capacity, dw: dry weight, fw: fresh weight. Results are expressed as the mean \pm standard deviation, $n=3$.

\subsection{Content and Retention Efficiency of Bioactive Compounds and Antioxidant Capacity in Microcapsules}

In order to avoid overestimation of the results due to the effect of GA used as wall material, the PC and AC in the blank (which consist in GA $10 \%$ W/W dried by SB and SFB) were quantified and subtracted from those obtained in the microcapsules. Content and retention efficiency of bioactive compounds and antioxidant capacity in microcapsules are shown in Figure 3a-c.

(a)

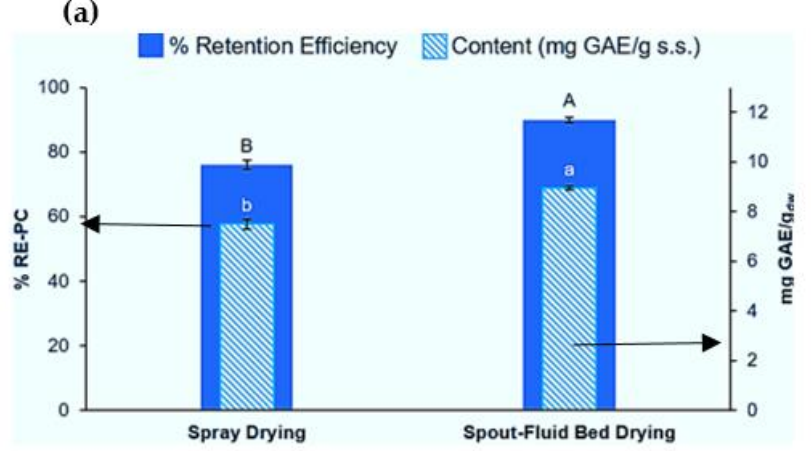

(b)

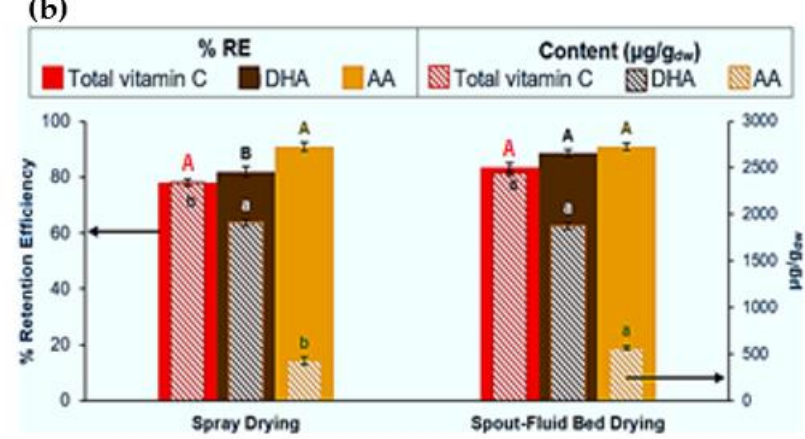

(c)

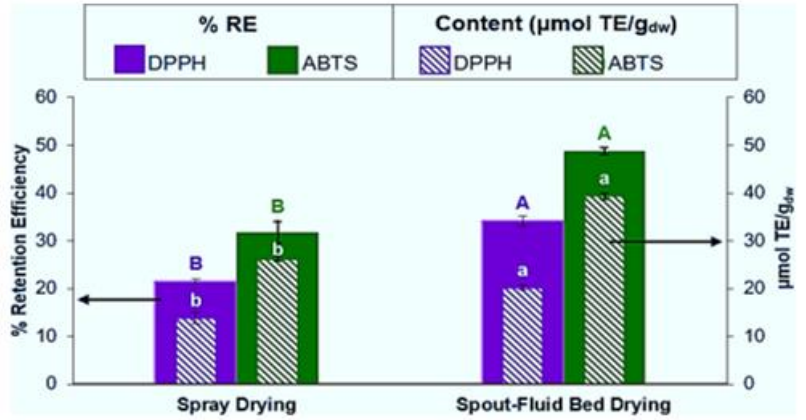

Figure 3. Content and retention efficiency of bioactive compounds and antioxidant capacity in microcapsules. (a) PC; (b) AA, DHA and total vitamin C; (c) antioxidant capacity (ABTS and DPPH). Data are expressed as the mean \pm standard deviation of the analysis in triplicate. The arrows indicate the axis to which the bars belong. RE: retention efficiency; PC: phenolic compounds; AA: ascorbic acid; DHA: dehydroascorbic acid. Different capital letters of the same color indicate significant difference of RE between spray drying and spout-fluid drying, and lower-case letters of the same color indicate significant difference in the content between spray drying and spout-fluid drying. 
The Retention Efficiency of PC in the microcapsules is shown in Figure 3a. The microcapsules obtained with SFB showed higher RE than microcapsules by SD $(90.05 \pm 0.9 \%$ and $76.04 \pm 1.3 \%$, respectively). The PC content in the microcapsules by SFB was $8.96 \pm 0.07 \mathrm{mg}$ $\mathrm{GAE} / \mathrm{g}_{\mathrm{dw}}$ and by SD $7.50 \pm 0.20 \mathrm{mg} \mathrm{GAE} / \mathrm{g}_{\mathrm{dw}}$. These PC values were higher than previous reported studies for SD (3.67-4.49 $\mathrm{mg} \mathrm{GAE} / \mathrm{g}$ ) [17] and SFB (3.95 mg GAE/g) [16] for $S$. purpurea pulp extract and pulp juice, respectively. The encapsulation efficiency (EE) of PC was $89.14 \pm 0.7 \%$ for SFB and $75.53 \pm 0.9 \%$ for SD, and almost all the PC retained was encapsulated.

Results for AA, DHA and total vitamin $C$ retention are shown in Figure $3 \mathrm{~b}$. The microcapsules obtained by SFB showed higher retention of DHA $(88.52 \pm 1.4 \%)$ than the microcapsules obtained by SD $(81.86 \pm 1.8)$; for the AA and total vitamin $C$ retention, no significant difference was observed between SD $(90.86 \pm 1.5 \%$ for AA and $78.10 \pm 1.3 \%$ for total vitamin C) and SFB $(90.80 \pm 1.2 \%$ for AA and $(83.30 \pm 1.8 \%$ for total vitamin C). There are few studies about Mexican plum bioactive compounds' encapsulation, and no studies have reported the DHA retention efficiency.

Regarding the content of AA, DHA and total AA in the microcapsules, shown in Figure 3b, microcapsules by SFB showed a higher content of AA (565 $\left.\pm 20 \mu \mathrm{g} \mathrm{AA} / \mathrm{g}_{\mathrm{dw}}\right)$ and total vitamin $\mathrm{C}\left(2442 \pm 21 \mu \mathrm{g} \mathrm{AA}+\mathrm{DHA} / \mathrm{g}_{\mathrm{dw}}\right)$ than SD $\left(429 \pm 45 \mu \mathrm{g} \mathrm{AA} / \mathrm{g}_{\mathrm{dw}}\right.$, and $\left.2343 \pm 38 \mu \mathrm{g} A \mathrm{~A}+\mathrm{DHA} / \mathrm{g}_{\mathrm{dw}}\right)$; for the DHA content, no significant difference was observed between SFB and SD. Maciel et al. [39] obtained similar AA content (466 $\mu \mathrm{g} \mathrm{AA/g}$ dw $)$ in the spray drying of Mexican plum juice, using maltodextrin $10 \mathrm{DE}$ as wall material. As can be seen in Figure 3b, in both drying methods, DHA content was higher than the AA content. This can be due to the high temperatures used in the drying process $\left(170{ }^{\circ} \mathrm{C}\right.$ for $\mathrm{SD}$ and $160^{\circ}$ for SFB) which could enhance oxidation of AA, and therefore produced an increase in DHA content [40].

Figure $3 \mathrm{c}$ shows the antioxidant capacity retention and the $\mathrm{AC}$ values. For both the ABTS and DPPH methods, the microcapsules obtained by SFB have the higher antioxidant capacity values and retention, and as can be seen, in all cases, the AC by ABTS was higher than DPPH because the ABTS method can determinate the AC of hydrophilic and lipophilic compounds, while the DPPH method only determines the AC from hydrophobic compounds [41]. Lins et al. [16] encapsulated Mexican plum extract by SFB and obtained a lower AC value than in this study; this could be due to the different extraction conditions (temperature, time, solvent, among others). Furthermore, in this study, both pulp and peel of Mexican plum were used and the peel has the major bioactive compounds content and, therefore, the major antioxidant capacity.

\subsection{Recovery and Bioaccessibility Indices of Bioactive Compounds and Antioxidant Capacity of Microcapsules Obtained by Spray Dried and Spout-Fluid Bed}

In order to avoid overestimation of the results, due to the presence of GA as wall material, the PC and AC in the blank (empty microcapsules) after the gastric and intestinal phase were also quantified and deducted from PC and AC in the microcapsules. As an easier and more economical alternative method of bioactive compound preservation, bioactive compound recovery and bioaccessibility in the dehydrated Mexican plum powder after in vitro digestion were compared to those obtained in the microcapsules by SD and SFB.

Recovery and bioaccessibility indices of phenolic compounds are shown in Figure 4a. The values for the extract alone and the dehydrated Mexican plum powder as an alternative method of preservation are shown as reference. The extract showed the lower RI and BI (31.31\% and $24.51 \%$, respectively), while the microcapsules by SD and the dehydrated Mexican plum powder showed the highest RI $(86.16 \%$ and $84.45 \%$, respectively), but at the end of the in vitro digestion, the higher BI was obtained for the SFB and SD microcapsules (63.61\% and 61.35\%, respectively). No significant difference in RI was found between dehydrated Mexican plum powder and microcapsules by SD; however, at the end of the intestinal phase, the BI of the Mexican plum powder had a significant decrease. According to Ketnawa et al. [42], the instability of the PC in the intestinal phase is due to enzymatic 
hydrolysis of phenolic and aromatic molecules, therefore, the phenolic compounds could change into their derivates (such as chalcones or quinones), which are unstable at high $\mathrm{pH}$ values.

(a)

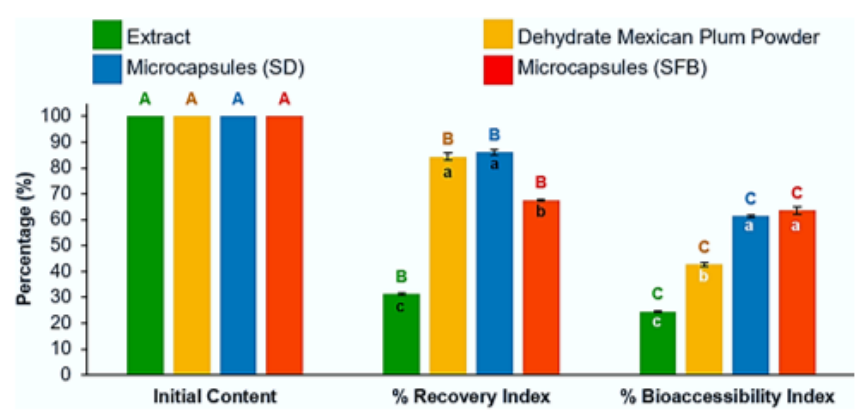

(c)

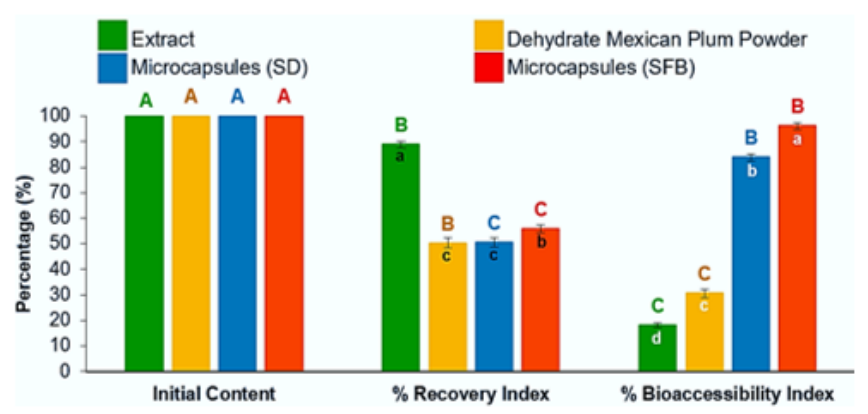

(e)

AC by ABTS

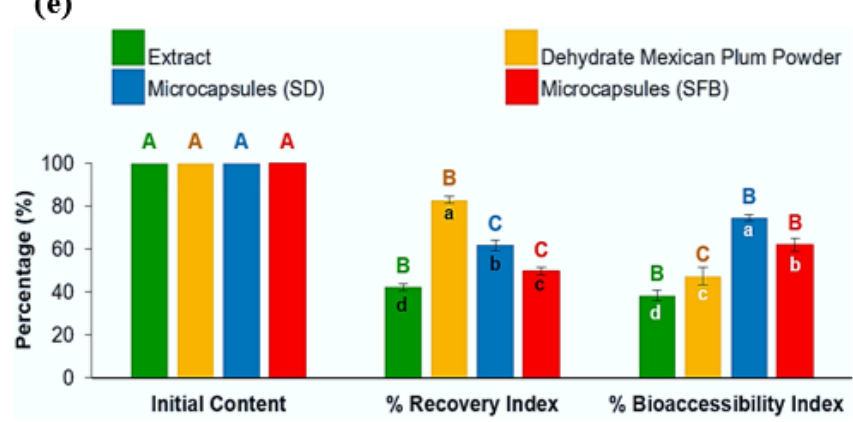

(b)

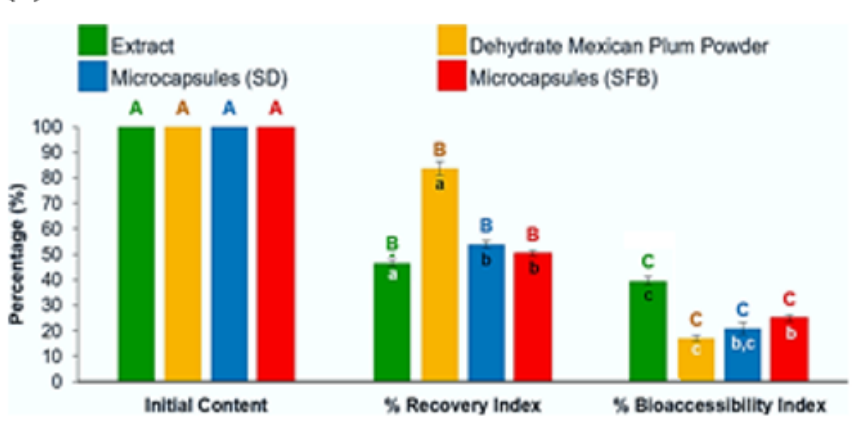

(d)

AA + DHA

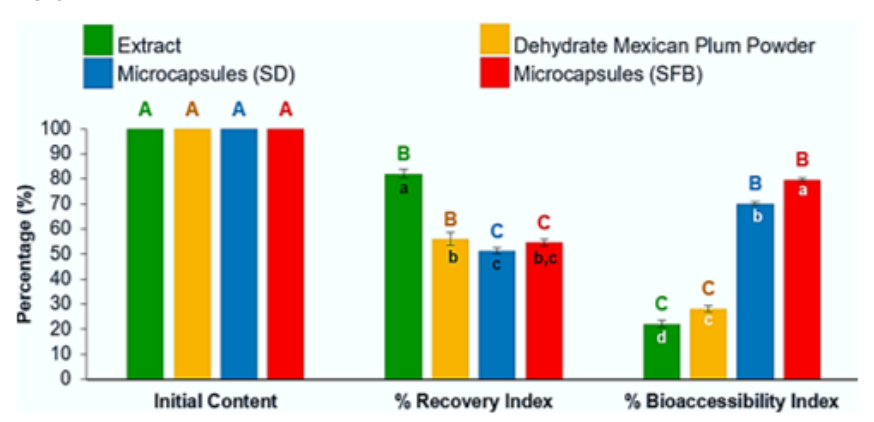

(f)

\section{AC by DDPH}

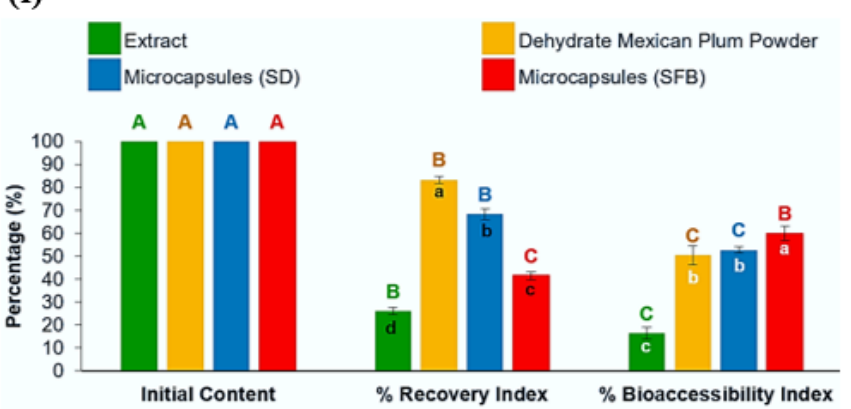

Figure 4. Recovery and Bioaccessibility indices of bioactive compounds and antioxidant capacity of microcapsules obtained by spray dried and spout-fluid bed. (a) Phenolic compounds (PC); (b) ascorbic acid (AA); (c) dehydroascorbic acid (DHA); (d) total vitamin C (AA+DHA); (e) antioxidant capacity by ABTS; (f) antioxidant capacity by DPPH. Data are expressed as the mean \pm standard deviation of the analysis in triplicate. SD: spray drying; SFB: spout-fluid bed drying; AC: antioxidant capacity. Different capital letters indicate significant difference in the same sample (extract, microcapsules and dehydrated Mexican plum powder), and lower-case letters indicate significant difference between group (initial content, recovery index and bioaccessibility index).

Recovery and bioaccessibility indices for AA, DHA and total vitamin $C$ are shown in Figure $4 \mathrm{~b}-\mathrm{d}$, respectively. Recovery Index of AA, DHA and total vitamin C (AA+DHA) in the extract was significantly $(p \leq 0.05)$ higher $(49.64 \%, 82.09 \%$ and $88.81 \%$, respectively) in comparison to that obtained after intestinal digestion (BI) for all compounds $(40.21 \%$ for AA, $18.26 \%$ for DHA and 20.01 for total vitamin C). Research works have reported losses of ascorbic acid after digestion with pepsin [15]. Studies have reported that ascorbic 
acid was more stable in acidic conditions than in alkaline [15]. During the gastric stage, the hydrochloric acid lowered the $\mathrm{pH}$ to 2.5 , which might help to increase the ascorbic acid stability. The loss of ascorbic acid during intestinal digestion could be due to $\mathrm{pH}(7)$ changes and the presence of oxygen after the enzymatic digestion process contributing to the ascorbic acid degradation.

SFB microcapsules showed the highest BI for DHA (96.19\%) and total vitamin C $(79.70 \%)$. Regarding AA, the highest RI was obtained for the Mexican plum powder $(83.60 \%)$, but the highest BI was obtained for the extract. No significant difference was observed for the AA in the BI between the microcapsules by SD and SFB. For both SD and SFB microcapsules, AA content significantly decreased at the end of the gastric and intestinal phases; however, the DHA and total vitamin C (DHA + AA) contents increased in the intestinal phase (BI). This could be explained by (enzymatic and no enzymatic) AA oxidation into DHA during simulated digestion [43]. These results agree with RodríguezRoque et al. [44], who reported that AA oxidization can occur after a long storage or after a heat or mechanic treatment, besides intestinal conditions, such as:neutral $\mathrm{pH}$, oxygen, temperature, enzymatic activity (ascorbate-oxidase) and the presence of minerals as copper and iron.

As is shown in Figure 4a-f, for Mexican plum extract without any protection and dehydrated plum powder, BI is always lower than RI (PC, AA, DHA, total vitamin C, ABTS, DPPH), but for microcapsules, this is not the case. The role of the microcapsules is to protect bioactive compounds from the gastric environment and release them in the intestine for possible absorption. As Figure 4 shows, this is the case for phenolic compounds but not for AA that is very unstable under digestion conditions.

Based on data shown in Figure 4b, both SD and SFB microcapsules did not protect AA, showing a reduction in AA of about $30 \%$ for SD and $27 \%$ for SFB microcapsules. If we assume that AA was oxidized to DHA due to $\mathrm{pH}$ and enzymic action on the molecule, then we would expect an increase of the same magnitude on DHA. Figure 4c shows that DHA increased from about $50 \%$ for $\mathrm{SD}$ and $55 \%$ for SFB microcapsules in the gastric digestion (RI) to about $80 \%$ (for SD) and about $90 \%$ for SFB in the intestinal digestion (BI), which is an increase of about the same order that was expected due to the loss of AA.

The microcapsules obtained by both drying methods proved to protect phenolic compounds, dehydroascorbic acid and total vitamin $C$ from degradation during in vitro digestion in the intestinal phase, where the highest percentages of bioaccessibility were obtained, compared to the extract without microencapsulation and the powder dehydrated Mexican plum.

The RI and BI for AC by ABTS and DPPH are shown in Figure 4e,f, respectively. The lowest RI and BI for the antioxidant capacity by ABTS and DPPH were observed in the extract. These results shown that the bioactive compounds in the extract, which have an antioxidant effect, are exposed and are more susceptible to degradation during the digestion process. The Mexican plum powder obtained higher RI for ABTS and DPPH than the extract and microcapsules, while the highest BI was obtained by SD microcapsules for ABTS and by SBD microcapsules for DPPH. These results show that the microencapsulation of Mexican plumb extract helps to avoid bioactive compounds' degradation that contributes to antioxidant capacity. It should be noted that the Mexican plum powder displayed a similar DPPH BI that of the SD microcapsules.

These results can be explained due to $\mathrm{pH}$ variations during digestion. These $\mathrm{pH}$ changes modify antioxidant capacity because antioxidants are more reactive and a major racemization occur at the gastric phase due to the acid $\mathrm{pH}$ and are less reactive at the intestinal phase because of the neutral $\mathrm{pH}$ (between 6 and 8) and, therefore, reduce the antioxidant capacity [45].

The results shows that bioactive compounds changes during the digestion process because of interactions among phenolic compounds or other dietary compounds released during the digestion, affecting their bioaccessibility. Microencapsulation of these com- 
pounds protect them from these changes, maintaining their bioactivity at the intestinal region, where they will be absorbed.

\subsection{Moisture Content and Water Activity $\left(a_{w}\right)$}

Table 2 shows the Moisture Content and Water Activity $\left(\mathrm{a}_{\mathrm{w}}\right)$. Moisture content is an important parameter to determine the shelf-life of microcapsules and indicates the residual water value on it. Values between 1 and $6 \%$ are desirable to preserve the stability during their storage [46]. Powders obtained by spray drying and spout-fluid bed drying had a moisture content of $3.95 \pm 0.01 \%$ and $2.25 \pm 0.43 \%$, respectively. No significant difference $(p<0.05)$ was observed. Similar values were obtained by Morais et al. [17] in spray drying of Mexican plum pulp extract using maltodextrin as wall material.

Table 2. Moisture Content and Water Activity $\left(\mathrm{a}_{\mathrm{w}}\right)$ of microcapsules obtained by spray drying and spout-fluid bed drying.

\begin{tabular}{ccc}
\hline Variable & Spray Drying & Spout-Fluid Bed Drying \\
\hline Moisture Content $(\%)$ & $3.95 \pm 0.10^{\mathrm{a}}$ & $2.25 \pm 0.43^{\mathrm{a}}$ \\
Water Activity $\left(\mathrm{a}_{\mathrm{w}}\right)$ & $0.25 \pm 0.01^{\mathrm{a}}$ & $0.26 \pm 0.03^{\mathrm{a}}$
\end{tabular}

Data are expressed as the mean \pm standard deviation of the analysis in triplicate. Different letters per row indicate significant statistical difference $(p \leq 0.05)$.

The water activity $\left(a_{\mathrm{w}}\right)$ is a parameter that indicates stability of a food product. Several authors have reported that $\mathrm{a}_{\mathrm{w}}$ values below 0.6 indicate that the product is stable at the microbiological and chemical level because of the low amount of free water available for biochemical reactions to occur [47]. The values of $\mathrm{a}_{\mathrm{w}}$ obtained by spray drying and spoutfluid bed drying were of $0.25 \pm 0.01$ and $0.26 \pm 0.03$, respectively (Table 2). According to the statistical analysis, no significant difference $(p<0.05)$ was observed. In this study, considering the low values of $\mathrm{a}_{\mathrm{w}}$ and moisture content of the powder obtained by spray drying and spout-fluid bed drying, good stability of these could be expected.

\subsection{Particle Size Distribution}

Particle size distribution of microcapsules obtained by SD and SFB is shown in Figure 5. As can been seen in Figure 5, a unimodal and narrow distribution was obtained for the microcapsules obtained by SD with particle size ranging from 1.22 to $46.40 \mu \mathrm{m}$, while the microcapsules by SFB had a unimodal and wide size distribution with particle size ranging from 3.65 to $350 \mu \mathrm{m}$. Similar values were obtained by Morais et al. [17] with particle size between 0.579 and $44 \mu \mathrm{m}$ in microcapsules by spray drying of $S$. purpurea extract, and by Costa et al. [48] with particle size between 0.06 and $600 \mu \mathrm{m}$ in microcapsules obtained by spout fluid bed drying of Euterpe oleracea extract.

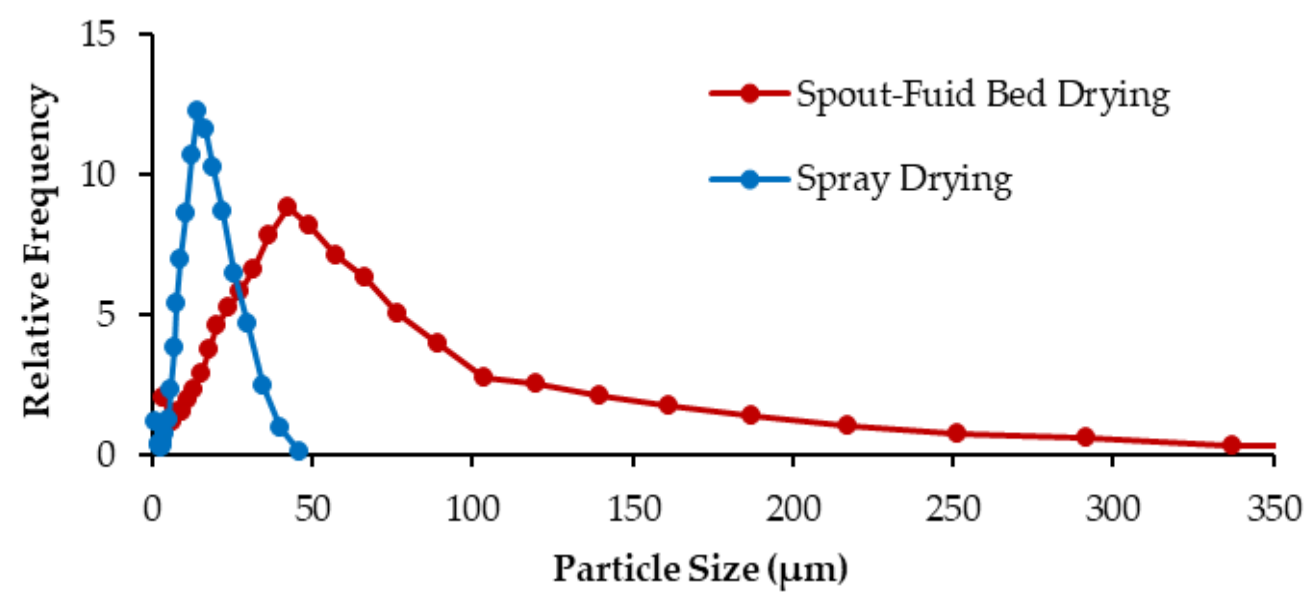

Figure 5. Particle size distribution of microcapsules obtained by spray drying and spout-fluid bed drying. 
Difference in particle size and particle size distribution between both drying methods was expected due to the different drying mechanism present. In SD, the sprayed droplets are dried by the hot air producing mainly shrunken spheres. For the SFB, the drying solution was sprayed over a bed of inert solids; the fed solution forms a coat on the surface of the inert particles, and this coat is stripped off when dried and brittle because of collisions, friction and shearing between the inert particles and dryer wall. Therefore, the microcapsules by SFB are in the forms of irregular flakes with a larger and varied particle size than microcapsules by SD.

Sauter diameter $(\mathrm{D}[3,2])$ and equivalent spherical diameter $(\mathrm{D}[4,3])$ were determined. The microcapsules by SD had $11.73 \pm 2.77 \mu \mathrm{m}$ for $\mathrm{D}[3,2]$ and $15.77 \pm 0.27 \mu \mathrm{m}$ for $\mathrm{D}[4,3]$, while the microcapsules by SFB showed $23.95 \pm 3.93 \mu \mathrm{m}$ and $52.94 \pm 2.93 \mu \mathrm{m}$, for D[3,2] and D[4,3], respectively.

The above results show that the drying mechanism had a significant effect in the bioactive compounds and antioxidant capacity retention. As shown by the above-mentioned results, higher retentions were obtained in SFB microcapsules which had a thicker wall than SD microcapsules. Additionally, according to Nikolić et al. [49], the microcapsules with a larger particle size have a better delayed release.

\subsection{Morphological Analyzes of Microcapsules}

Image shape and particle surface morphology obtained by scanning electron microscopy (SEM) of microcapsules of Mexican plum extract obtained by both spray drying and spout-fluid bed drying are shown in Figure 6. As can be seen in Figure 6a, microcapsules obtained by spray drying show the typical sphere shape obtained in this equipment. Most of these particles show a shrunken surface due to the permeability of the wall that allows the diffusion of water vapor out of the particles during drying. No broken particles can be appreciated. On average, the size of the particles is around 15-20 $\mu \mathrm{m}$, which is in agreement with the particle size distribution shown in Figure 5.

\section{Flake shape particles}

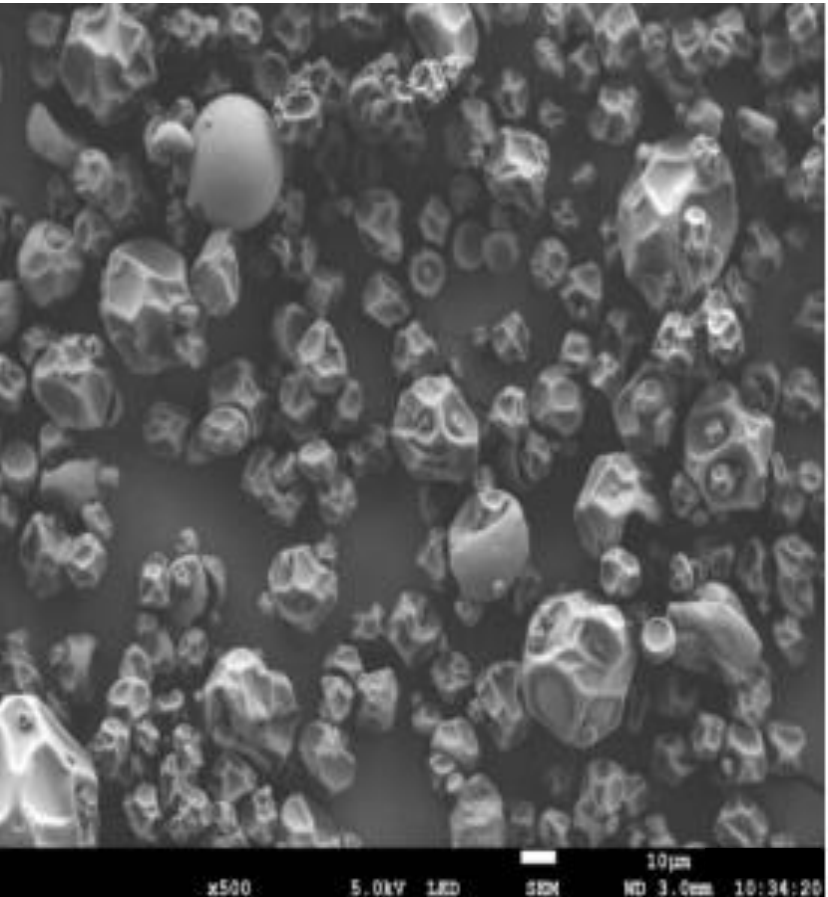

(a)

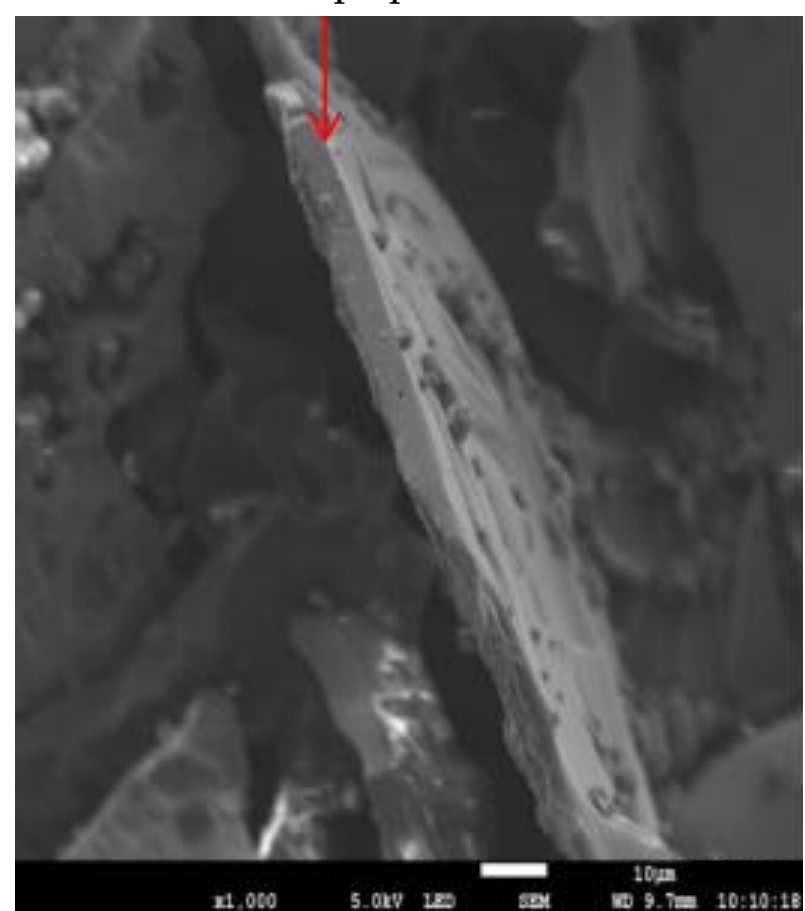

(b)

Figure 6. Image of microcapsules under the scanning electron microscope of Mexican plum microencapsulated by (a) spray drying, 500× magnification and (b) spout-fluid bed drying, 1000× magnification, all at $15 \mathrm{kV}$. 
Regarding the microcapsules obtained by spout-fluid bed drying (Figure 6b), due to the different drying mechanism in which a layer of the feed dries on the inert particles surface, when they are dried and brittle enough, they are released by the collisions among particles and inner tube. As Figure $6 \mathrm{~b}$ shows, most particles collected in the cyclone separator are pieces of flakes of about $7 \mu \mathrm{m}$ in thickness, with widespread particle size much larger than spray drying particles. Figure $6 \mathrm{~b}$ also shows the presence of a small number of spherical particles, which are due the spray drying of fines during feeding of the solution to be dried.

Difference in shape, wall thickness and size of microcapsules obtained by both drying methods confer different release rates of bioactive compounds during in vitro digestion.

\section{Conclusions}

The present study shows that Mexican plum pulp and peel are a good source of PC, vitamin C (as AA and DHA) and AC. The optimal extraction conditions were: three consecutive extractions at $40{ }^{\circ} \mathrm{C}$, for $90 \mathrm{~min}$ and aqueous ethanol concentration of $40 \%$. SD and SFB microcapsules were able to protect the bioactive compounds present in the extract and avoid their degradation during the in vitro digestion process (60\% PC, 70-80\% total vitamin C, $60-70 \%$ AC by ABTS and $50-60 \%$ AC by DPPH). Microcapsules obtained by SFB showed a better bioactive compound protection and, therefore, antioxidant capacity retention than SD microcapsules.

Dried Mexican plum powder as an alternative preservation method of bioactive compounds was able to preserve, after in vitro digestion, a higher content of bioactive compounds and, hence, antioxidant capacity than the extract; nevertheless, these were lower than those preserved by the microcapsules.

Since Mexican plum is a seasonal fruit and has a short postharvest life, microencapsulation of its bioactive compounds is a good option to preserve them during storage and protect them during in vitro digestion. Moreover, Mexican plum microcapsules are a free-flowing powder product and can be used as an ingredient rich in natural antioxidants that can be incorporated into food matrices as food supplements to develop functional foods in the food industry. Future studies in vivo are needed to confirm the biological activities of the powders.

Author Contributions: Conceptualization: S.L.A.-C., O.G.M.-M. and G.O.-R.; Methodology: S.L.A.-C., T.G.-V., O.G.M.-M. and G.O.-R.; Formal Analysis: T.G.-V., O.G.M.-M. and G.O.-R.; Investigation: S.L.A.-C.; Resources: O.G.M.-M. and G.O.-R.; Writing-Original Draft Preparation: S.L.A.-C.; Writing-Review and Editing: O.G.M.-M. and G.O.-R.; Visualization: T.G.-V., O.G.M.-M. and G.O.-R.; Supervision: O.G.M.-M. and G.O.-R.; Project Administration: O.G.M.-M. and G.O.-R.; Funding Acquisition: O.G.M.-M. and G.O.-R. All authors have read and agreed to the published version of the manuscript.

Funding: Authors thank the Instituto Politécnico Nacional for the financial support through grant SIP-20200128. S.L.A.-C. wishes to express her gratitude to Consejo Nacional de Ciencia y Tecnología (CONACyT) for the scholarship provided with number 932407.

Institutional Review Board Statement: Not applicable.

Informed Consent Statement: Not applicable.

Data Availability Statement: Data used to support the findings of this study can be requested from ogmmz@yahoo.com.mx (O.G.M.-M.). Tel.: +52-(55)-5729-6000 (ext. 57877); osorgi@gmail.com (G.O.-R.). Tel.: +52-(55)-5729-6000 (ext. 57817).

Acknowledgments: The authors wish to express their gratitude to Escuela Nacional de Ciencias Biológicas-Instituto Politécnico Nacional (ENCB-IPN) for providing the financial support for the present study.

Conflicts of Interest: The authors declare no conflict of interest. 


\section{References}

1. Tovar, S.H.M.; Ballesteros-Patrón, G.A.; Robledo, A.P.; Cruz, L.A. Botánica de Spondias L. (Anacardiaceae): Jocotes, jobos, abales o ciruelas mexicanas en México. In Jocotes, Jobos, Abales o Ciruelas Mexicanas; Cruz, L.A., Duque, A.P., Haros, B.R., Eds.; Universidad Autónoma de Chapingo: Estado de México, Mexico, 2012; Volume 2, pp. 11-26.

2. Vargas-Simón, G. Ciruela/Mexican Plum. Spondias purpurea L. In Exotic Fruits Reference Guide; Rodríguez, S., Oliveira, E., de Brito, E.S., Eds.; Elsevier: London, UK, 2018; pp. 141-152.

3. Avitia, G.; González, A.C.; Barrios, A.M.P. Ciruela Mexicana y Otras Especies del Género Spondias L.; Universidad Autónoma de Chapingo: Estado de México, Mexico, 2012; pp. 1-30.

4. Solorzano-Morán, S.; Alia-Tejacal, I.; Rivera-Cabrera, F.; López-Martínez, V.; Pérez-Flores, L.J.; Pelayo-Zaldívar, C.; GuillénSánchez, D.; León-Sánchez, F.D.; Maldonado-Astudillo, Y.I. Quality attributes and functional compounds of Mexican plum (Spondias purpurea L.) fruit ecotypes. Fruits 2015, 70, 261-270. [CrossRef]

5. García-González, M.; Alia-Tejacal, I.; Rivera-Cabrera, F.; Díaz de León, S.F.; López-Martínez, V.; Pérez-Flores, L.J.; Pelayo-Zaldivar, C. Refrigeración de ciruela mexicana (Spondias purpurea L.) 'Cuernavaqueña'. Acta Agrícola Y Pecu. 2016, 2, 27-33.

6. $\quad$ Engels, C.; Gräter, D.; Esquivel, P.; Jiménez, V.M.; Gänzle, M.G.; Schieber, A. Characterization of phenolic compounds in jocote (Spondias purpurea L.) peels by ultra high-performance liquid chromatography/electrospray ionization mass spectrometry. Food Res. Int. 2012, 46, 557-562. [CrossRef]

7. Macedo, D.A.; Mafaldo, I.M.; Oliveira, P.M.L.; Lima, M.S.; Magnani, M.; Borges, G.S.C. Bioaccessibility of phenolic compounds in native and exotic frozen pulps explored in Brazil using a digestion model coupled with a simulated intestinal barrier. Food Chem. 2019, 274, 202-214.

8. Augustin, M.A.; Sanguansri, L. Encapsulation of bioactives. In Food Materials Science. Principles and Practice; Aguilera, J.M., Lillford, P.J., Eds.; Springer: New York, NY, USA, 2008; pp. 577-583.

9. Đorđević, V.; Balanč, B.; Belščak-Cvitanović, A.; Lević, S.; Trifković, K.; Kalušević, A.; Kostić, I.; Komes, D.; Bugarski, B.; Nedović, V. Trends in Encapsulation Technologies for Delivery of Food Bioactive Compounds. Food Eng. Rev. 2015, 7, 452-490. [CrossRef]

10. Minekus, M.; Alminger, M.; Alvito, P.; Balance, S.; Bohn, T.; Bourlieu, C.; Carrière, F.; Boutrou, R.; Corredig, M.; Dupont, D.; et al. A standardised static in vitro digestion method suitable for food-an international consensus. Food Funct. 2014, 5, $1113-1124$. [CrossRef]

11. Mansour, M.; Salah, M.; Xu, X. Effect of microencapsulation using soy protein isolate and gum arabic as wall material on red raspberry anthocyanin stability, characterization, and simulated gastrointestinal conditions. Ultrason. Sonochemistry 2020, 63, 104927-104935. [CrossRef]

12. Bharathi, S.K.V.; Moses, J.A.; Anandharamakrishnan, C. Nano and microencapsulation using food grade polymers. In Polymers for Food Applications; Gutiérrez, T.J., Ed.; Springer: New York, NY, USA, 2018; pp. 357-386.

13. Gulão, S.; De Suouza, C.J.F.; Fernanda, A.S.; Coimbra, J.S.R.; García-Rojas, E.E. Complex coacervates obtained from lactoferrin and gum arabic: Formation and characterization. Food Res. Int. 2014, 65, 367-374. [CrossRef]

14. Hosseni, A.; Jafari, S.M.; Mirzaei, H.; Asghari, A.; Akhavan, S. Application of image processing to assess emulsion stability and emulsification properties of Arabic gum. Carbohydr. Polym. 2015, 126, 1-8. [CrossRef]

15. Sollano-Mendieta, X.C.; Meza-Márquez, O.G.; Osorio-Revilla, G.; Téllez-Medina, D.I. Effect of in vitro digestion on the antioxidant compounds and antioxidant capacity of 12 plum (Spondias purpurea L.) ecotypes. Foods 2021, 10, 1995. [CrossRef]

16. Lins, A.D.F.; Rocha, A.P.T.; Gomes, J.P.; Feitosa, R.M.; Araujo, G.T.; Santos, D.C. Adsorption isotherms of the red mombin powder produced in spouted bed dryer. Rev. Bras. Eng. Agrícola E Ambient. 2017, 21, 562-567. [CrossRef]

17. Morais, B.D.M.; Júnior, M.E.S.; Andrade, S.A.C.; Converti, A.; Silva, M.F.; Maciel, M.I.S. Optimization of red mombin juice spray drying: Physicochemical and sensory analyses of powders. Chem. Eng. Technol. 2020, 43, 1832-1840. [CrossRef]

18. Hernández-Ruiz, K.L.; Ruiz-Cruz, S.; Cira-Chávez, L.A.; Gassos-Ortega, L.E.; Ornelas-Paz, J.J.; Del Toro-Sánchez, C.L.; MárquezRíos, E.; López-Mata, M.A.; Rodríguez-Félix, F. Evaluation of antioxidant capacity, protective effect on human erythrocytes and phenolic compound identification in two varieties of plum fruit (Spondias spp.) by UPLC-MS. Molecules 2018, 23, 3200. [CrossRef] [PubMed]

19. Robert, P.; Gorena, T.; Romero, N.; Sepulveda, E.; Chávez, J.; Saenz, C. Encapsulation of polyphenolns and anthocyanins from pomegranate (Punica granatum) by spray drying. Int. J. Food Sci. Technol. 2010, 45, 1386-1394. [CrossRef]

20. Rigon, R.T.; Zapata, N.C.P. Microencapsulation by spray-drying of bioactive compounds extracted from blackberry (Rubus fruticosus). J. Food Sci. Technol. 2016, 53, 1515-1524. [CrossRef]

21. Osorio-Revilla, G.; Elías-Serrano, R.; Gallardo-Velázquez, T. Drying of liquid feedstocks in a spout-fluid bed with draft-tube submerged in inert solids: Hydrodynamics and drying performance. Can. J. Chem. Eng. 2008, 82, 142-147. [CrossRef]

22. Osorio-Revilla, G.; Gallardo-Velázquez, T.; Ramírez-Torres, A.; Rivera-Espinoza, Y. Residence time distribution in spouted bed drying of maltodextrin solutions on a bed of inert particles. Can. J. Chem. Eng. 2012, 90, 153-162. [CrossRef]

23. Velázquez-Contreras, C.; Osorio-Revilla, G.; Gallardo-Velázquez, T. Encapsulation of Orange Essential Oil in a Spout-Fluid Bed Dryer with a Draft Tube on a Bed of Inert Solids. Drying Technol. 2014, 5, 1718-1726. [CrossRef]

24. González-Montelongo, R.; Gloria, L.M.; González, M. Antioxidant activity in banana peel extracts: Testing extraction conditions and related bioactive compounds. Food Chem. 2010, 119, 1030-1039. [CrossRef]

25. Giusti, M.M.; Wrolstad, R.E. Anthocyanins. Characterization and Measurement of Anthocyanins by UV Visible Spectroscopy. In Current Protocols in Food Analytical Chemistry; Wrolstad, R., Ed.; Wiley: New York, NY, USA, 2001; pp. 21-30. 
26. Omaye, S.T.; Turnbull, D.; Sauberlich, H.E. Selected methods for the determination of ascorbic acid in animal cells, tissues, and fluids. Methods Enzymol. 1979, 62, 3-11.

27. Zieliński, H. Contribution of low molecular weight antioxidants to the antioxidant screen of germinated soybean seeds. Plant Foods Hum. Nutr. 2003, 58, 1-20. [CrossRef]

28. Re, R.; Nicoletta, P.; Proteggente, A.; Pannala, A.; Yang, M.; Rice-Evans, C. Antioxidant activity applying an improved ABTS radical cation decolorization assay. Free. Radic. Biol. Med. 1999, 26, 1231-1237. [CrossRef]

29. Brand-Williams, W.; Cuvelier, M.E.; Berset, C. Use of a Free Radical Methods to Evaluate Antioxidant Activity. LWT-Food Sci. Technol. 1995, 28, 25-30. [CrossRef]

30. Toledo-Madrid, K.; Gallardo-Velázquez, T.; Osorio-Revilla, G. Microencapsulation of purple cactus pear fruit (Opuntia ficus indica) extract by the combined method $\mathrm{W} / \mathrm{O} / \mathrm{W}$ double emulsion-spray drying and conventional spray drying: A comparative study. Process 2018, 6, 189. [CrossRef]

31. Boyano-Orozco, L.; Gallardo-Velázquez, T.; Meza-Márquez, O.G.; Osorio-Revilla, G. Microencapsulation of rambutan peel extract by spray drying. Foods 2020, 9, 899. [CrossRef]

32. Ortega, N.; Macià, A.; Romero, M.P.; Reguant, J.; Motilva, M.J. Matrix composition effect on the digestibility of carob flour phenols by an in vitro digestion model. Food Chem. 2011, 124, 65-71. [CrossRef]

33. Stafussa, A.P.; Maciel, G.M.; Rampazzo, V.; Bona, E.; Makara, C.N.; Junior, B.D.; Haminiuk, C.W.I. Bioactive compounds of 44 traditional and exotic Brazilian fruit pulps: Phenolic compounds and antioxidant activity. Int. J. Food Prop. 2018, 21, 106-118. [CrossRef]

34. Suárez-Vargas, A.; Juárez-López, P.; López-Martínez, V.; Pérez, L.J.; Guillén, D.; Alia-Tejacal, I. Botânica e fisiologia/botany and physiology antioxidant activity and physicochemical parameters in "cuernavaqueña" mexican plum (Spondias purpurea L.) at different ripening stages. Rev. Bras. Frutic. 2016, 39, 1-10.

35. Moo-Huchin, V.; Estrada-Mota, I.; Estrada-León, R.; Cuevas-Glory, L.; Ortiz-Vázquez, E.; Vargas-Vargas, M.L.; Betancur-Ancona, D.; Sauri-Duch, E. Determination of some physicochemical characteristics, bioactive compounds and antioxidant activity of tropical fruits from Yucatan, Mexico. Food Chem. 2014, 152, 508-515. [CrossRef]

36. Vasco, C.; Ruales, J.; Kamal-Eldin, A. Total phenolic compounds and antioxidant capacities of major fruits from Ecuador. Food Chem. 2008, 111, 816-823. [CrossRef]

37. Almeida, M.M.B.; Sousa, P.H.M.; Arriaga, Â.M.C.; Prado, G.M.; Magalhães, C.E.C.; Maia, G.A.; Lemos, T.L.G. Bioactive compounds and antioxidant activity of fresh exotic fruits from northeastern Brazil. Food Res. Int. 2011, 44, 2155-2159. [CrossRef]

38. Cacace, J.E.; Mazza, G. Extraction of anthocyanins and other phenolics from black currants with sulfured water. J. Agric. Food Chem. 2002, 50, 5939-5946. [CrossRef] [PubMed]

39. Maciel, M.I.S.; dos Santos, N.C.; Júnior, M.E.S.; Souza, M.M.B. Efeito da umidade relative e do tempo de armezenamento sob os compostos fitoquímicos do suco de ciriguela (Spondias purpurea L.) atomizado. In Proceedings of the XXV Congreso Brasileiro de Ciência e Tecnología de Alimentos, Sao Paulo, Brazil, 26 October 2016; pp. 6-8.

40. Wechtersbach, L.; Polak, T.; Ulrih, N.P.; Cigić, B. Stability and transformation of products formed from dimeric dehydroascorbic acid at low pH. Food Chem. 2011, 129, 965-973. [CrossRef] [PubMed]

41. Santos-Félix, A.C.; Novaes, C.G.; Rocha, M.P.; Barreto, G.E.; do Mascimento, B.B.; Giraldez-Álvarez, L.D. Mixture design and doehlert matrix for the optimization of the extraction of phenolic compounds from Spondias mombin L. apple bahasse agroindustrial residues. Food Chem. 2018, 5, 116.

42. Ketnawa, S.; Suwannachot, J.; Ogawa, Y. In vitro gastrointestinal digestion of crisphead lettuce: Changes in bioactive compounds and antioxidant potential. Food Chem. 2020, 311, 125885. [CrossRef]

43. Ydjedd, S.; Bouriche, S.; Nicolás, R.L.; Sánchez-Moya, T.; Frontela-Saseta, C.; Ros-Berruezo, G.; Rezgui, F.; Louaileche, H.; Kati, D.E. Effect of in vitro gastrointestinal digestion on encapsulated and nonencapsulated phenolic compounds of carob (Ceratonia siliqua) pulp extracts and their antioxidant capacity. J. Agric. Food Chem. 2017, 65, 827-835. [CrossRef]

44. Rodríguez-Roque, M.J.; Rojas-Graü, M.A.; Elez-Martínez, P.; Martín-Belloso, O. In vitro bioaccessibility of health-related compounds as affected by the formulation of fruit juice- and milk- based beverages. Food Res. Int. 2014, 62, 771-778. [CrossRef]

45. Chen, G.L.; Chen, S.G.; Chen, F.; Xie, Y.Q.; Han, M.D.; Zhao, Y.Y.; Gao, Y.Q. Nutraceutical potential and antioxidant benefits of selected fruit seeds subjected to an in vitro digestion. J. Funct. Foods 2016, 20, 317-331. [CrossRef]

46. Zhang, J.; Zhang, C.; Chen, X.; Quek, Y.S. Effect of spray drying on phenolic compounds of cranberry juice and their stability during storage. J. Food Eng. 2020, 269, 109744-109754. [CrossRef]

47. Eroglu, E.; Tontul, İ.; Topuz, A. Optimization of aqueous extraction and spray drying conditions for efficient processing of hibiscus blended rosehip tea powder. J. Food Processing Preserv. 2018, 42, 13643. [CrossRef]

48. Costa, R.G.; Andreola, K.; Mattietto, R.A.; Faria, L.J.G.; Taranto, O.P. Effect of operating conditions on the yield and quality of açai (Euterpe oleracea Mart.) powder produced in spouted bed. Food Sci. Technol. 2015, 64, 1196-1203. [CrossRef]

49. Nikolić, N.C.; Stanisavljević, N.; Šavikin, K.; Kaluševic, A.; Nedović, V.; Bigović, D.; Janković, A.T. Application of gum arabic in the production of psray-dried chokeberry polyphenols, microparticles characterisation and in vitro digestion method. Lek. Sirovine 2018, 38, 9-16. [CrossRef] 